\title{
Formulation of Longitudinal Flexion Creases: Validation of Inheritance, Twin Diagnosis and Ethnic Variation
}

\author{
Anjali Pandey ${ }^{1}$, A. N. Sharma ${ }^{2}$ \\ ${ }^{1}$ Research Scholar, Department of Anthropology, Dr. H. S. Gour University, Sagar (Madhya Pradesh), India 470003 \\ ${ }^{2}$ Professor, Head, Department of Anthropology, Dr. H. S. Gour University, Sagar (Madhya Pradesh), India 470003
}

\begin{abstract}
In the palm there are three longitudinal and two transverse creases are present. The longitudinal creases are present on thenar, central and hypothenar area, while the transverse are distal and proximal crease. Here an attempt is made to formulate new classification of tranverse flexion creases their validation of inheritance, twin diagnosis and ethnic variation. This classification is more effectively applied in the study of ethnic variations etc. For the validity of the classification 100 families of Gonds and 126 pairs of twins (including di-zygotic and mono zygotic) were investigated simultaneously, the formulation is tested through the study of two populations i.e., Kacchis and Gonds 150 males and 150 females, unrelated individuals were selected from each group, from Sagar district, Madhya Pradesh, India. The results exhibit inheritance and ethnic variation.
\end{abstract}

Keywords: Thenar, hypothenar, longitudinal, transverse, proximal crease etc.

\section{Introduction}

In general, 3 major palmar flexion creases are exhibit in the palm i.e., radial longitudinal crease, distal transverse crease and proximal transverse crease. Features of creases, because of their permanency, unchangeability and individualistic uniqueness: are most suitable for the study of inheritance, Personal identification, sexual dimorphism, racial variability, association with some diseases including mental abnormalities and twin diagnosis. Khatoon et al., (1990) studied in details the reliability of creases in twin zygosity. The diagnosis of Symmetrical and Asymmetrical occurrence of creases were studied by Sharma and Bali (1983).

Doi and Yamanaka (2003) used palmar creases as the feature points of finger for personal authentification. Again Doi and Yamanaka (2003), They analysed flexion creases through the palmar geometry and integrated with personal authentication.

Bali and Choubey (1971) can accommodate several creases types of various classification and can help to rearrange the existing material on palmer flexion creases. The various types and subtypes of the creases can logically fit in their three fold scheme of classification. Siobham M. Mattinson et al (2015), are given a new classification of palmar creases, reliability of palmar creases in their relationship with Fetal Alcohol Spectram disorders (FASD).

Various researchers presented the different-different formulations of palmar flexion creases viz., Bhanu (1972), Kwlatkowska et al (2014) Bali and chobe (1971) and, Bali and Sharma (1989), Taura et at (2014), and Roszaharah Yaacoob et al (2015), which are not much effective in the study of human variations. To solve this problem, here an attempt is made to present a new palmar crease formulation, in which attempt have been made to remove problems of palmar classification.
The objective of the present study is to establish a new formulation of longitudinal flexion creases and prove the validation through inheritance, twin diagnosis and ethnic variation.

\section{Material and method}

The data were collected from Sagar district of Madhya Pradesh, India. Sagar district is situated in north-east area of Madhya Pradesh, it lies between latitude 23.83' north and longitude 78.71' east. For the present study 100 families of Gonds population were examine for the study of inheritance. The Gonds is the principal tribe of the Dravidian family and it's a important non-aryan tribe or forest tribe in India. It is Second largest populated tribe of India. The 126 pairs of twins (mono-zygotic and di-zygotic) were examine for twin diagnosis. The mono-zygotic and di-zygotic twins were identified on the bases of number of placenta.

The 150 males and 150 females' individuals were selected from two endogamous groups i.e., Gonds and Kacchis. The Gonds are the largest tribal community in India, who are belong to Dravidian family and traced as pre Dravidian era. The Kacchis are also an endogamous caste of India; it is an important cultivating caste of India, who grows vegetables and irrigated crops requiring intensive cultivation. Data were collected randomly from unrelated individuals. For taken the bilateral prints of palm the method prescribed by Cummins and Midlo (1961) is fully adopted. For the analysis of transverse flexion crease the new proposed formulation is adopted, the formulation of transverse flexion creases is as follow:

\section{Proposed New Classification}

The proposed new classification of longitudinal flexion crease is based on three main longitudinal creases i.e., radial longitudinal crease (life line on the palm), sagittal 


\section{International Journal of Science and Research (IJSR) \\ ISSN (Online): 2319-7064 \\ Index Copernicus Value (2013): 6.14 | Impact Factor (2015): 6.391}

longitudinal crease (line of fate), and the ulnar crease (line of mercury) emerged from the carpal area of the palm. On the basis of their point of origin longitudinal flexion creases are divided in deferent categories i.e.,

1) Longitudinal flexion creases I (LFC I) : In this condition only radial longitudinal crease is present on the palm. (Fig.1)

2) Longitudinal flexion creases II (LFC II) : In this case radial longitudinal crease is present in natural manner whereas sagittal crease occur straight (towards $3^{\text {rd }}$ digit), and the base of sagittal crease joints with radial longitudinal crease. (Fig.2)

3) Longitudinal flexion creases III (LFC III) : In this condition the sagittal longitudinal crease joints at the base end on the radial longitudinal crease and runs upward toward $\mathrm{I}^{\text {st }}$ inter digital area. (Fig.3)

4) Longitudinal flexion creases IV (LFC IV) : In this case sagittal longitudinal crease joint at the base of radial longitudinal crease and runs toward ulnar side. (Fig.4)

5) Longitudinal flexion creases V (LFC V) : In This condition only radial longitudinal crease and ulnar creases are present. The ulnar crease joints at the base of radial longitudinal crease (Fig.5).

6) Transverse flexion creases VI (LFC VI) : In this condition radial longitudinal crease, sagittal longitudinal crease and ulnar crease joints at the base. (Fig.6)

7) Longitudinal flexion creases VII (LFC VII) : In this condition radial longitudinal crease and sagittal longitudinal creases are separated at the base and sagittal longitudinal crease occurs more or less straight in manner. (Fig.7)

8) Longitudinal flexion creases VIII (LFC VIII) : In this case radial longitudinal crease and sagittal longitudinal crease are separated at the base, while sagittal longitudinal crease terminal end runs toward radial side. (Fig.8)

9) Longitudinal flexion creases IX (LFC IX) : In this condition only radial longitudinal crease and sagitttal longitudinal crease occur on the palm and separated at the base. The sagittal longitudinal crease terminal end runs towards ulnar side. (Fig.9)

10) Longitudinal flexion creases $X$ (LFC $X$ ) : In this condition radial longitudinal crease and ulnar crease occur on the palm and separated from each other at the base. (Fig.10)

11) Longitudinal flexion creases (LFC XI) : In this case radial longitudinal crease and sagittal longitudinal crease joint at the base while ulnar crease occurs separately (Fig.11).

12) Longitudinal flexion creases XII (LFC XII) : In this condition sagittal longitudinal crease and ulnar crease joint at the base, while radial longitudinal occurs separated from the sagittal longitudinal crease and ulnar crease. (Fig.12)

13) Longitudinal flexion creases XIII (LFC XIII) : In this case radial longitudinal crease and ulnar crease joints at the base and sagittal longitudinal crease occurs separately (Fig.13).

14) Longitudinal flexion creases XIV (LFC XIV) : In this condition all the three creases i.e., radial longitudinal crease, sagittal longitudinal crease and ulnar crease occurs on the palm, and separated at the base from each other. (Fig.14)

The method has been applied on families, Twins and other populations segments. The incidence of palmar flexion crease on the individual palm of the offsprings born of the respective parents show their heritable significance. Thus indicating the validity of the present method of classification of palmar crease and indicates that the trait is genetically controlled. For the statistical analysis chi-square test of independency was applied as the data are qualitative in nature.
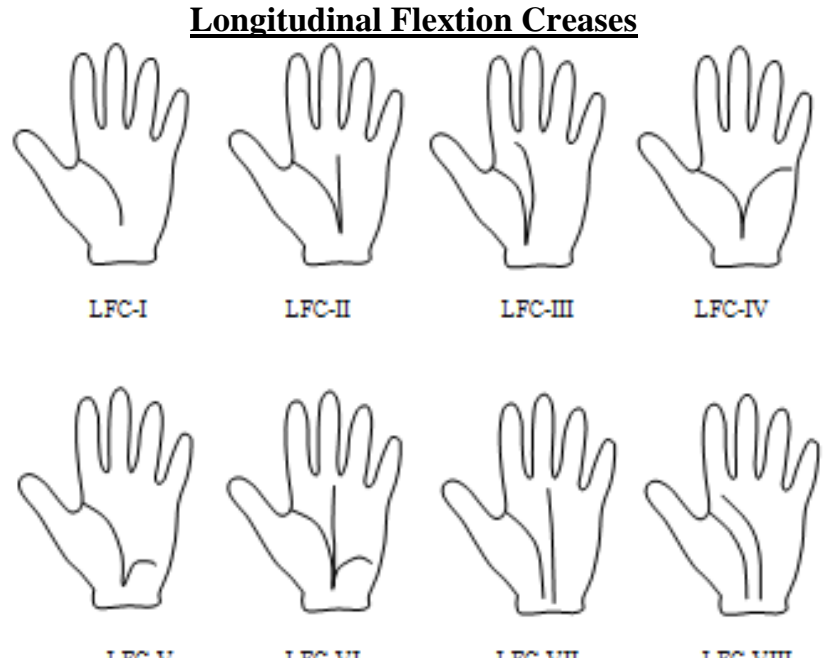

LFC-V

LFC-VI

LFC-VII

LFC-VIII
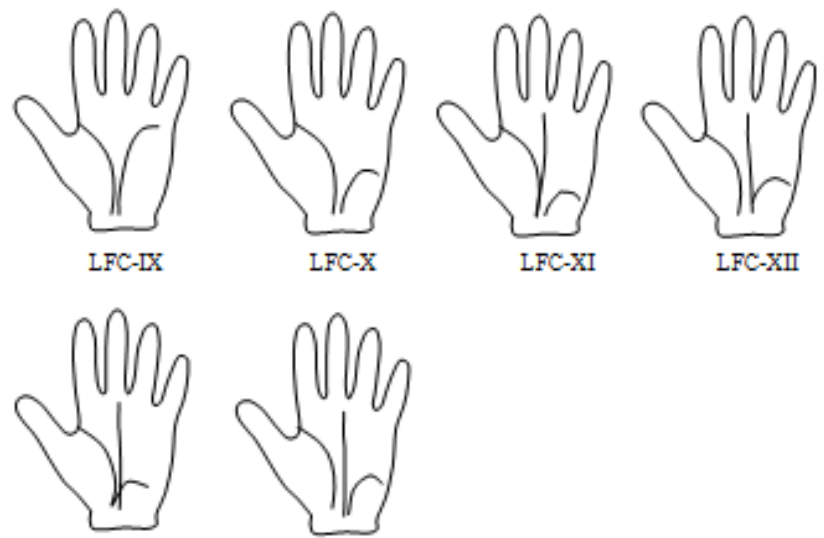

\section{Result and Discussion}

The tables related to inheritance, twin diagnosis and ethnic variations of longitudinal flexion creases are presented in the following manner:

Table 1: Statistical analysis of inheritance of longitudinal flexion creases of father's vs. male offsprings.

Father's right hand and left hand Vs. son's right hand and left hand

\begin{tabular}{|l|l|ll|}
\hline $\begin{array}{c}\text { S. } \\
\text { No. }\end{array}$ & \multicolumn{1}{|c|}{ Father Vs. Son } & $\begin{array}{r}\text { Chi-square test of independency } \\
\mathrm{df}=6 ; \mathrm{p}<0.05\end{array}$ \\
\hline 1. & Father Rt Vs. son Rt & $\chi^{2}$ & $=3.24$ (insignificant) \\
\hline 2. & Father Rt Vs. son Lt & $\chi^{2}$ & $=2.38$ (insignificant) \\
\hline 3. & Father Lt Vs. son Rt & $\chi^{2}$ & $=2.36$ (insignificant) \\
\hline 4. & Father Lt Vs. son Lt & $\chi^{2}$ & $=4.24$ (insignificant) \\
\hline 5. & Father Rt+ Lt Vs. son Rt +Lt & $\chi^{2}$ & $=3.63$ (insignificant) \\
\hline
\end{tabular}

*Rt- Right hand,* Lt - Left hand, *df-degree of freedom, *p- Level of significant 


\section{International Journal of Science and Research (IJSR) \\ ISSN (Online): 2319-7064 \\ Index Copernicus Value (2013): 6.14 | Impact Factor (2015): 6.391}

Table 1 shows statistical analysis of inheritance patterns of longitudinal flexion creases in terms of fathers vs. male offspring. It could be seen from the table that all the male offsprings exhibits insignificant chi-square value. It means that the frequency of palmar longitudinal flexion creases of father's and male off springs are more or less same. It may be concluded from the table that longitudinal flexion creases are inherited from father to their male offsprings clearly.

Table 2: Statistical analysis of inheritance of longitudinal flexion creases of mothers vs. male offspring.

Mothers right hand and left hand Vs. son's right hand and left hand

\begin{tabular}{|c|c|cc|}
\hline $\begin{array}{c}\text { S. } \\
\text { No. }\end{array}$ & Mother Vs. Son & $\begin{array}{c}\text { Chi-square test of independency } \\
\mathrm{df}=6 ; \mathrm{p}<0.05\end{array}$ \\
\hline 1. & Mother Rt Vs. son Rt & $\chi^{2}$ & $=3.36$ (insignificant) \\
\hline 2. & Mother Rt Vs. son Lt & $\chi^{2}$ & $=2.06$ (insignificant) \\
\hline 3. & Mother Lt Vs. son Rt & $\chi^{2}$ & $=3.5$ (insignificant) \\
\hline 4. & Mother Lt Vs. son Lt & $\chi^{2}$ & $=1.78$ (insignificant) \\
\hline $\begin{array}{c}\text { 5. } \\
\text { Mother Rt + Lt Vs. son } \\
\text { Rt +l Lt }\end{array}$ & $\chi^{2}$ & $=4.58$ (insignificant) \\
\hline
\end{tabular}

*Rt- Right hand,* Lt - Left hand, *df-degree of freedom, *p- Level of significant

Table 2 shows statistical analysis of inheritance patterns of longitudinal flexion creases in terms of mothers and male off springs. It could be observed from the table that all the male offsprings exhibits insignificant chi-square value. It means that the frequency of palmar longitudinal flexion creases of mothers and male off springs are more or less same.

It may be concluded from the table that longitudinal flexion creases are inherited from mother to their male off spring

Table 3: Statistical analysis of inheritance of longitudinal flexion creases of father's vs. female offspring.

Father's right hand and left hand Vs. daughter's right hand and left hand

\begin{tabular}{|c|c|cc|}
\hline $\begin{array}{c}\text { S. } \\
\text { No. }\end{array}$ & Father Vs. Daughter & $\begin{array}{c}\text { Chi-square test of independency } \\
\mathrm{df}=6 ; \mathrm{p}<0.05\end{array}$ \\
\hline 1. & Father Rt Vs. daughter's Rt & $\chi^{2}$ & $=4.43$ (insignificant) \\
\hline 2. & Father Rt Vs. daughter's Lt & $\chi^{2}$ & $=4.01$ (insignificant) \\
\hline 3. & Father Lt Vs. daughter's Rt & $\chi^{2}$ & 1.53 (insignificant) \\
\hline 4. & Father Lt Vs. daughter's Lt & $\chi^{2}$ & $=1.47$ (insignificant) \\
\hline 5. & $\begin{array}{c}\text { Father Rt + Lt Vs. daughter's } \\
\text { Rt + Lt }\end{array}$ & $\chi^{2}$ & $=4.83$ (insignificant) \\
\hline
\end{tabular}

*Rt- Right hand,* Lt - Left hand, *df-degree of freedom, *p- Level of significant

Table 3 shows statistical analysis of inheritance patterns of longitudinal flexion creases in terms of fathers and female offsprings. It could be observed from the table that all female offsprings exhibit insignificant chi-square value. It means the frequency of palmar longitudinal flexion creases of fathers and female offsprings are more or less same. It may be concluded from the table that longitudinal flexion creases are inherited from father to their female offspring.
Table 4: Statistical analysis of inheritance of longitudinal flexion creases of father's and their female offspring. Mothers right hand and left hand Vs. daughter's right hand and left hand

\begin{tabular}{|c|c|lr|}
\hline $\begin{array}{c}\text { S. } \\
\text { No }\end{array}$ & Mothers Vs. Daughter & $\begin{array}{r}\text { Chi-square test of independency } \\
\mathrm{df}=6 ; \mathrm{p}<0.05\end{array}$ \\
\hline 1. & Mother Rt Vs. daughter's Rt & $\chi^{2}$ & $=1.49$ (insignificant) \\
\hline 2. & mother Rt Vs. daughter's Lt & $\chi^{2}$ & $=0.39$ (insignificant) \\
\hline 3. & mother Lt Vs. daughter's Rt & $\chi^{2}$ & $=1.71$ (insignificant) \\
\hline 4. & Mother Lt Vs. daughter's Lt & $\chi^{2}$ & $=1.13$ (insignificant) \\
\hline 5. & $\begin{array}{c}\text { Mother Rt+ Lt Vs. daughter's } \\
\text { Rt +Lt }\end{array}$ & $\chi^{2}$ & $=1.51$ (insignificant) \\
\hline
\end{tabular}

*Rt- Right hand,* Lt- Left hand, *df-degree of freedom, *pLevel of significant

Table 4 shows statistical analysis of inheritance patterns of longitudinal flexion creases in terms of mothers and female off springs. It could be observed from the table that all the female offsprings exhibit insignificant chi-square value. It means the frequency of palmar longitudinal flexion creases of mothers and female off springs are more or less same. It indicates that longitudinal flexion creases are inherited from mother to their female off spring.

Table: 5. Concordance and dis-concordance of longitudinal flexion creases among di-zygotic and mono zygotic twins.

\begin{tabular}{|c|c|c|c|c|c|c|}
\hline \multirow{2}{*}{ Twins } & \multirow{2}{*}{ No. } & \multirow{2}{*}{ Side } & \multicolumn{2}{c|}{ Concordance } & \multicolumn{2}{c|}{ Dis-concordance } \\
\cline { 3 - 7 } & & & $\mathbf{A b}$ & $\mathbf{P c}$ & $\mathbf{A b}$ & $\mathbf{P c}$ \\
\hline \multirow{2}{*}{$\begin{array}{c}\text { Mono-zygotic twin } \\
\text { (MZ) }\end{array}$} & 54 & $\mathrm{Rt}$ & 44 & 81.48 & 10 & 18.52 \\
\cline { 2 - 7 } & $\mathrm{Lt}$ & 48 & 88.89 & 6 & 11.11 \\
\cline { 3 - 7 } & $\mathrm{Rt}+\mathrm{Lt}$ & 92 & 85.18 & 16 & 14.81 \\
\hline \multirow{2}{*}{$\begin{array}{c}\text { Di-zygotic twins } \\
\text { (DZ) }\end{array}$} & 72 & $\mathrm{Rt}$ & 57 & 79.17 & 15 & 20.83 \\
\cline { 2 - 6 } & $\mathrm{Lt}$ & 53 & 73.61 & 19 & 26.39 \\
\cline { 3 - 6 } & $\mathrm{Rt}+\mathrm{Lt}$ & 110 & 76.89 & 34 & 23.61 \\
\hline
\end{tabular}

* Ab : Absolute number, Pc : Percentage

The table 5 shows concordance and dis-concordance among $\mathrm{DZ}$ twins and MZ twins. It could be observed from the table that MZ twins show $81.48 \%$ concordance and $18.52 \%$ disconcordance in right hands, while the DZ twins show $79.17 \%$ concordance and $20.83 \%$ dis-concordance in right hands. The left hands of MZ twins show 88.89\% concordance and $11.11 \%$ dis-concordance, while DZ twins show $73.61 \%$ concordance and $26.39 \%$ dis-concordance among left hands.

While considering Right and left hands (Rt+Lt) both combined, it is observed that MZ twins show 85.18\% concordance and $14.81 \%$ dis-concordance, while the DZ twins shows $76.89 \%$ concordance and $23.61 \%$ of disconcordance. The results are clearly showing that the MZ twins have more similarities as compared to DZ twins.

Table 6: Concordance and dis-concordance among dizygotic twins of like sex and unlike sex

\begin{tabular}{|c|c|c|c|c|c|c|}
\hline \multirow{2}{*}{ Twins } & \multirow{2}{*}{ No. } & \multirow{2}{*}{ Side } & \multicolumn{2}{c|}{ Concordance } & \multicolumn{2}{c|}{ Dis-concordance } \\
\cline { 4 - 7 } & & & $A b$ & $P c$ & $A b$ & $P c$ \\
\hline $\begin{array}{c}\text { Di-zygotic twins } \\
\text { like sex }\end{array}$ & 48 & $\mathrm{Rt}$ & 32 & 66.67 & 16 & 33.33 \\
\cline { 3 - 7 } & $\mathrm{Lt}$ & 35 & 72.92 & 13 & 27.08 \\
\cline { 3 - 7 } & $\mathrm{Rt}+\mathrm{Lt}$ & 67 & 69.79 & 29 & 30.20 \\
\hline $\begin{array}{c}\text { Di-zygotic twins } \\
\text { unlike sex }\end{array}$ & 24 & $\mathrm{Rt}$ & 15 & 62.5 & 9 & 37.5 \\
\cline { 2 - 6 } & $\mathrm{Lt}$ & 13 & 54.17 & 11 & 45.83 \\
\cline { 2 - 6 } & $\mathrm{Rt}+\mathrm{Lt}$ & 28 & 58.33 & 20 & 41.67 \\
\hline
\end{tabular}

Ab : Absolute number, ${ }^{*}$ Pc : Percentage 


\section{International Journal of Science and Research (IJSR) \\ ISSN (Online): 2319-7064 \\ Index Copernicus Value (2013): 6.14 | Impact Factor (2015): 6.391}

The table 6 shows concordance and dis-concordance among like sex and unlike sex of DZ twins. It could be observed from the table that DZ twins of like sex show $66.67 \%$ concordance and $33.33 \%$ dis-concordance in right hands, while the DZ twins of unlike sex show $62.5 \%$ concordance and $37.5 \%$ dis-concordance in right hands. The left hands of like sex of DZ twins show $72.92 \%$ concordance and $27.08 \%$ dis-concordance, while DZ twins of unlike sex show $54.17 \%$ concordance and $\mathbf{4 5 . 8 3 \%}$ dis-concordance in left hands.

While considering both the hands (Rt+Lt) combined, it may be observed from the table that DZ twins of like sex show $69.79 \%$ concordance and $30.20 \%$ dis-concordance, and DZ twins of unlike sex show $58.33 \%$ concordance and $41.67 \%$ dis-concordance.

It could be summarized from the table that the longitudinal flexion creases are heritable traits. The study of twins by the above longitudinal flexion creases also confirms fact that the proposed method of crease formulation is valid and useful in the study of population and genetics.

Table 7: Frequency distribution of longitudinal flexion creases of kacchis and Gonds right hands of males'

\begin{tabular}{|c|c|c|c|c|c|}
\hline \multirow{2}{*}{ S. No. } & Crease formulation type & \multicolumn{2}{|c|}{ Kacchi } & \multicolumn{2}{c|}{ Gonds } \\
\cline { 3 - 6 } & & Ab & Pc & Ab & Pc \\
\hline 1. & LFC I & 53 & 35.33 & 72 & 48.0 \\
\hline 2. & LFC II & 28 & 18.67 & 22 & 14.67 \\
\hline 3. & LFC III & 10 & 6.67 & 2 & 1.33 \\
\hline 4. & LFC IV & 8 & 5.33 & 4 & 2.67 \\
\hline 5. & LFC V & 1 & 0.67 & 5 & 3.33 \\
\hline 6. & LFC VI & 0 & 0.0 & 2 & 1.33 \\
\hline 7. & LFC VII & 22 & 14.67 & 26 & 17.33 \\
\hline 8. & LFC VIII & 15 & 10.0 & 7 & 4.67 \\
\hline 9. & LFC IX & 9 & 6.0 & 7 & 4.67 \\
\hline 10. & LFC X & 2 & 1.33 & 1 & 0.67 \\
\hline 11. & LFC XI & 1 & 0.67 & 0 & 0.0 \\
\hline 12. & LFC XII & 0 & 0.0 & 0 & 0.0 \\
\hline 13. & LFC XIII & 1 & 0.67 & 2 & 1.33 \\
\hline 14. & LFC XVI & 0 & 0.0 & 0 & 0.0 \\
\hline & Total & $\mathbf{1 5 0}$ & $\mathbf{9 9 . 9 9}$ & $\mathbf{1 5 0}$ & $\mathbf{9 9 . 9 9}$ \\
\hline
\end{tabular}

*Rt- Right hand,* Lt - Left hand, *df-degree of freedom, ${ }^{*}$ p- Level of significant

$\chi^{2}=22.11, \mathrm{p}<0.05, \mathrm{df}=7$,(significant)

Table 7 is showing frequency distribution of longitudinal flexion creases among Gonds and Kacchis right hands of males. It may be observed from the table that LFC I type of crease shows highest frequency among Gonds (35.33) and Kacchis (48.0). The LFC V, LFC XI and LFC XIII show lowest frequency among Kacchis (0.67), while among the Gonds LFC X show lowest frequency.

It may be concluded that LFC I type of crease shows highest frequency among Kacchis and Gonds and shows significant ethnic variation. The various type of creases show significant chi-square value. It indicates ethnic variation among Kacchi and Gond male right hands are concerned.
Table 8: Frequency distribution of longitudinal flexion creases of Kacchis and Gonds left hands of males'

\begin{tabular}{|c|c|c|c|c|c|}
\hline \multirow{2}{*}{ S. No. } & \multirow{2}{*}{ Crease formulation } & \multicolumn{2}{|c|}{ Kacchi } & \multicolumn{2}{|c|}{ Gonds } \\
\cline { 3 - 6 } & & Ab & Pc & Ab & Pc \\
\hline 1. & LFC I & 42 & 28.0 & 62 & 41.33 \\
\hline 2. & LFC II & 25 & 16.67 & 25 & 16.67 \\
\hline 3. & LFC III & 6 & 4.0 & 7 & 4.67 \\
\hline 4. & LFC IV & 13 & 8.67 & 4 & 2.67 \\
\hline 5. & LFC V & 2 & 1.33 & 7 & 4.67 \\
\hline 6. & LFC VI & 0 & 0.0 & 2 & 1.33 \\
\hline 7. & LFC VII & 25 & 16.67 & 22 & 14.67 \\
\hline 8. & LFC VIII & 21 & 14.0 & 8 & 5.33 \\
\hline 9. & LFC IX & 8 & 5.33 & 4 & 2.67 \\
\hline 10. & LFC X & 4 & 2.67 & 4 & 2.67 \\
\hline 11. & LFC XI & 1 & 0.67 & 0 & 0.0 \\
\hline 12. & LFC XII & 0 & 0.0 & 2 & 1.33 \\
\hline 13. & LFC XIII & 1 & 0.67 & 2 & 1.33 \\
\hline 14. & LFC XVI & 2 & 1.33 & 1 & 0.67 \\
\hline & Total & $\mathbf{1 5 0}$ & $\mathbf{9 9 . 9 9}$ & $\mathbf{1 5 0}$ & $\mathbf{9 9 . 9 9}$ \\
\hline
\end{tabular}

*Rt- Right hand,* Lt - Left hand, *df-degree of freedom, *p- Level of significant

$\chi^{2}=27.11, \mathrm{p}<0.05, \mathrm{df}=7$,(significant)

Table 8. shows frequency distribution of longitudinal flexion creases among Gonds and Kacchis left hands of males. It could be seen from the table that LFC I type of crease shows highest frequency among Gonds (28.0) and Kacchis (41.33). The LFC XI and LFC XIII type of crease shows lowest frequency among Gonds (0.67), while among Kacchis LFC XVI shows lowest frequency (0.67).

It may be concluded that LFC I type of shows highest frequency among Gond and Kacchis. The various type of creases show significant chi-square value. It indicates ethnic variation among Kacchi and Gond male left hands are concerned.

Table 9: Frequency distribution of longitudinal flexion creases of kacchis and Gonds both hands (Rt+Lt) combined of males'

\begin{tabular}{|c|c|c|c|c|c|}
\hline \multirow[t]{2}{*}{ S. No. } & \multirow[t]{2}{*}{ Crease formulation } & \multicolumn{2}{|c|}{ Kacchi } & \multicolumn{2}{|c|}{ Gonds } \\
\hline & & $A b$ & $P c$ & $A b$ & $P c$ \\
\hline 1. & LFC I & 95 & 31.67 & 134 & 44.67 \\
\hline 2. & LFC II & 53 & 17.67 & 47 & 51.67 \\
\hline 3. & LFC III & 16 & 5.33 & 9 & 3.00 \\
\hline 4. & LFC IV & 21 & 7.33 & 8 & 2.67 \\
\hline 5. & LFC V & 3 & 1.0 & 12 & 4.0 \\
\hline 6. & LFC VI & 0 & 0.0 & 4 & 1.67 \\
\hline 7. & LFC VII & 47 & 15.67 & 48 & 16.0 \\
\hline 8. & LFC VIII & 36 & 12.0 & 15 & 5.0 \\
\hline 9. & LFC IX & 17 & 5.67 & 11 & 3.67 \\
\hline 10. & LFC X & 6 & 2.0 & 5 & 1.67 \\
\hline 11. & LFC XI & 2 & 0.67 & 0 & 0.0 \\
\hline 12. & LFC XII & 0 & 0.0 & 2 & 0.67 \\
\hline 13. & LFC XIII & 2 & 0.67 & 4 & 1.67 \\
\hline 14. & LFC XVI & 2 & 0.67 & 1 & 0.33 \\
\hline & Total & 300 & 99.99 & 300 & 99.99 \\
\hline
\end{tabular}

*Rt- Right hand,* Lt - Left hand, *df-degree of freedom, ${ }^{*}$ p- Level of significant $\chi^{2}=43.26, p<0.05, \mathrm{df}=7$,(significant)

Table 9 shows frequency distribution of longitudinal flexion creases among Gonds and Kacchis both hands (Rt+Lt) of males. It may be observed from the table that LFC I type of crease shows highest frequency among Gonds (31.67) and 


\section{International Journal of Science and Research (IJSR) \\ ISSN (Online): 2319-7064 \\ Index Copernicus Value (2013): 6.14 | Impact Factor (2015): 6.391}

Kacchis (44.67). The LFC XI, LFC XII and LFC XVI shows lowest frequency among Gonds, while among Kacchis LFC XVI type of crease shows lowest frequency (0.33).

It may be concluded that LFC I type of crease shows highest frequency among Gonds and Kacchis. The various type of creases show significant chi-square value. It indicates ethnic variation among Kacchi and Gond males both hands (Rt+Lt) combined right hands are concerned.

It could be summarized from the above discussion that the longitudinal flexion creases are heritable traits. The study of twins and ethnic variation by the above longitudinal flexion creases also confirms fact that the proposed method of crease formulation is valid and useful in the study of population studies, twins identification and inheritance.

\section{References}

[1] Bali, R.S. \& Choube, R. (1971): On the formulation of palmar creases, Z. Morph. Anthropology 61 (1): 121130.

[2] Bali, R.S. and Sharma, A.N. (1989): Creases as a diagnostic tools in personal identification. Crease Anthropology, 91: 95, Northern Book Center Publishers, New Delhi, 100-110.

[3] Bhanu, V. (1972): Simian Crease in man: Some methodological considerations. J. Hum. Evol. 2: 152155.

[4] Junta Doi and Yamanaka M. (2003): Personal authentication by integrating palmar geometry and flexion crease analysis. Conference vol. 5048, Nondestructive detection and measurement for Homeland security, 83 (July 21, 2003)

[5] Junta Doi and Yamanaka M. (2003): Personal authentication using feature points on finger and palmar creases. Workshop of Applied imagery Pattern Recognition in Narashino, Japan, 282-287.

[6] Khatoon, S., Khan M.F.H., Choube, R. and Bali, R.S. (1990) : Inheritance of transverse palmar flexion creases, Inter. Conf. Progress and trends in dermatoglyphic Research, Calcutta.

[7] Kwlatkowska, M., Jakutowlcz, T., Clazek, B. and Czubak, J. (2014): Cum plamar crease serve as landmark for the deeper neuro-vascrlar strnctures, Surg. Radiol. Anat. 36:495-501.

[8] Roszaharah Yacoob, Rafaqat Hussain, and Puwira Jaya (2015) : Comparition of creases at palm prints among three generations of Malay race in Malaysia. Internation postgraduation conference, University of Teknologi, Malaysia.

[9] Sharma, A.N. and Bali, R.S. (1983) : The occurrence of symmetrical Asymmetrical Palmar Creases. Human Biology: Recent advances, Today \& Tomorrow's Printer and Publishers, New Delhi 590-600.

[10] Siobham M. Mattison, Emily K. Brunson and Darryl Holman (2015): Palmar Creases: Classification Reliability and Relationship of Fetal Alcohol Spectrum Disorders (FASD), Coll. Anthro. 39 (3) : 769-774.

[11] Taura Minu A., Magaji G. and Adamu H (2014) : Palmar creases : A comparative study between epilepsy patients and healthy subjects among Hausas of Northern
Nigeria; American jour. of Medicine and medical science, 4 (5) : 175-179. 